\title{
Percepçõese saberes da equipe de saúde e de familiares de crianças menores de dois anos sobre a atenção em saúde bucalinfantil na Atenção Primária a Saúde
}

Perceptions and knowledge of the patient care team and family members of children under two years old about oral health in Primary Health Care

Percepciones y conocimientosdel equipo de saludy los membros de la família de niños menores de dos años sobre laatención de lasalud bucal enAtención Primaria de Salud

Caroline Longaray de Oliveira

Maria Lucia Medeiros Lenz

Roberta Garcia

Daniel Demétrio Faustino-Silva ${ }^{1}$

RESUMO: A Unidade de Saúde(US) Nossa Senhora Aparecida (NSA) realiza o acompanhamento de Puericultura com consultas individuais e coletivas focando no trabalho multidisciplinar. Sabese que a atenção odontológica na primeira infânciatem grande relevância, à medida que ocorrem diversas mudanças na cavidade oral nesse período. Sendo assim, orientações referentes aos cuidados com higiene bucal, alimentação saudável e hábitos deletérios são de responsabilidade de toda a equipe. Assim, o objetivo desse estudo foi avaliar a percepção e o conhecimento dos familiares de crianças menores de 2 anos de idade e profissionais de saúde da US NSA sobre a importância da atenção à saúde bucal nesse período. Essa foi uma pesquisa qualitativa do tipo descritiva exploratória, cujas informações foram coletadas em grupos focais, sendo um grupo com os profissionais de saúde da equipe e outro com familiares que compareceram apenas às consultas individuais de puericultura; entrevistas individuais em profundidade foram realizadas com familiares que compareceram às consultas coletivas. Os resultados obtidos nesse estudo sugerem que o conhecimento de pais e responsáveis de crianças menores de 2 anos e profissionais de saúde acerca dos cuidados com a saúde bucal no primeiro ano de vida ainda é bastante empírico

1 Especialista em Saúde da Família, Mestrado em Odontopediatria, Doutor em Saúde Bucal Coletiva

ISSN 1982-8829 Tempus, actas de saúde colet, Brasília, 13(3), 61-77, set, 2019. Epub Jul/2020 
e permeado pelas experiências individuais e familiares que ambos vivenciam. Dessa forma, reforçase a necessidade de realização de ações educativas sistemáticas para os profissionais de saúde e a importância da abordagem familiar ao usuário visando melhor compreensão do seu contexto, hábitos e valores, a fim de promover ações preventivas e educativas com maior efetividade.

Palavras-chave: Cuidado da Criança. Saúde Bucal. Pesquisa Qualitativa. Atenção Primária à Saúde. Saúde Materno-Infantil.

ABSTRACT: The Health Center NossaSenhoraAparecida (NSA) performs the Child Care through individual and collective appointments in the first year of life with a focus on multidisciplinary work. Studies reinforce the importance of dental care in this period based on changes that occur in the oral cavity and require orientations to care providers regarding oral hygiene, diet and harmful habits prevention. Therefore, it is known that such guidelines are not only dentist's responsibility. The main goal of this study was to evaluate the perception and knowledge of the relatives of children less than 2 years old and NSA's health professionals about the importance of dental health care in the first year of life. This was a qualitative and descriptive exploratory research, whose information was collected in focus groups, one group formed by healthprofessionals who carry out collective appointments on childcare and another group with family members who attended only individual childcare consultations, and individual interviews with relatives who attended the collective appointments. The results obtained from this research suggest that the knowledge of parents of children under than 2 years old andhealth professionals about dental health care in the first year of life is still very empirical and permeated by individual and family experiences. Thus, it's reinforced the need for systematic educational actions for health professionals and the importance of the familiar approach to the user in order to better understand their context, habits and values, for the purpose of promote preventive and educational actions with greater effectiveness.

Key-words: Child Care.Oral Health. Qualitative Research. Primary Health Care. Maternal and Child Health.

RESUMEN: El Centro de Salud Nossa Senhora Aparecida lleva a cabo elmonitoreodelcuidado delniñoconcitasmédicasindividualesycolectivascentradaseneltrabajomultidisciplinario. Saludbucal enniños menores de dos años es de granrelevancia, a medida que occurenmuchoscambiosenlacavidad oral. Por lo tanto, las pautas relacionadas com el cuidado de la higiene bucal, laconducta alimentaria y los hábitos nocivos son responsabilidade del grupo de atención al paciente. El propósito de esta investigaciónfueevaluarlapercepción y elconocimiento de los membros de la família de niños menores de dos años y personales de saluddel Centro de Salud Nossa Senhora Aparecida sobre laatencion de lasalud bucal durante este período. Esta fue una investigacióncualitativacon grupos focales, siendoun grupo conpersonales de salud y otroconmiembros de la família que asistieron solo a citas médicas individuales. Se realizaron entrevistas individuales em profundidadconmiembros de la família que asistieron a las citas médicas colectivas. Los resultados de esta investigaciónsugieren que elconocimientode los padres y cuidadores de niños menores de dos años y personales de salud sobre el cuidado de lasalud oral es muy empírico y esta influenciado por lasexperienciasindividuales 
y familiares de ambos. Por lo tanto, laimportancia y necessidad de acciones educativas para lospersonales de salud y laimportancia de un enfoque familiar para los familiares conel objetivo de comprendermejorsu contexto, hábitos y valores, conelfin de promover acciones preventivas y educativas conmayoreficacia.

Palabras clave: Cuidado delNiño. Salud Bucal. InvestigaciónCualitativa.Atención Primaria de Salud.Salud Materno-infantil.

\section{INTRODUÇÃO}

O Brasil teve ao longo dos últimos anos uma redução considerável nos índices de mortalidade infantil ${ }^{1}$, o que tem sido atribuído à atenção materno-infantil prestada na Atenção Primária à Saúde (APS), dentre outros fatores. Desse modo, vale ressaltar que o Ministério da Saúde (MS) preconiza o desenvolvimento de ações na APS com ênfase no acompanhamento do desenvolvimento infantil, incentivando o aleitamento materno e a prevenção e controle de infecções ${ }^{2}$. Nesse contexto, o Programa de Puericultura, por sua vez, consiste no acompanhamento periódico e sistemático das crianças para a avaliação do seu desenvolvimento e crescimento, do calendário vacinal, do aleitamento materno, da identificação de agravos, bem como, visa a oferecer orientações alimentares e de higiene aos familiares e responsáveis ${ }^{3,4,5}$, incluindo os cuidados de saúde bucal infantil ${ }^{6,2}$. Sendo assim, os profissionais envolvidos nesse acompanhamento devem estar aptos a realizar ações educativas, que vão além do atendimento clínico e focam em questões epidemiológicas e sociais, a partir do trabalho multiprofissional, pautado no cuidado humanizado que valoriza o saber da família.

O presente estudo foca no acompanhamento realizado através de consultas individuais e coletivas de puericultura e consultas odontológicas, durante o primeiro ano de vida da criança, na Unidade de Saúde (US) Nossa Senhora Aparecida (NSA), uma das doze unidades de APS do Serviço de Saúde Comunitária do Grupo Hospitalar Conceição (SSC-GHC). As rotinas de atenção às crianças no primeiro ano de vida, tal como é preconizado pelo Ministério da Saúde, priorizam ao menos 7 consultas de puericultura durante esse período. A primeira deve acontecer na primeira semana de vida e as subsequentes recomendam-se aos 30 dias, 2, 4, 6, 9 e 12 meses, visando faixas etárias adequadas para a realização das imunizações, orientações oportunas quanto à prevenção de doenças e agravos e o monitoramento do crescimento e desenvolvimento ${ }^{5,2}$. Isto posto, a US NSA conta com uma equipe de saúde ampliada e segue o mesmo protocolo de consultas e acompanhamento durante primeiro ano de vida conforme reforça a literatura ${ }^{5,7}$, entretanto, para além disso, são oferecidas consultas coletivas multiprofissionais para as crianças com 2, 6 e 9 meses de idade. Essas consultas contam sempre com a presença de 3 profissionais de diferentes formações, médico ou enfermeiro, junto com outros dois profissionais de saúde, que podem ser psicólogo, odontólogo, nutricionista ou assistente social, a fim de ampliar o cuidado e promover uma atenção mais integral.

O cuidado odontológico focado na saúde bucal da criança no primeiro ano de vida inicia ainda

ISSN 1982-8829 Tempus, actas de saúde colet, Brasília, 13(3), 61-77, set, 2019. Epub Jul/2020 
durante o período gestacional, através da realização do Pré-natal odontológico ${ }^{5,8}$. Além disso, o acesso ao dentista nessa faixa etária deve ser priorizado pelas equipes de saúde através de estratégias que englobam diferentes possibilidades, como consultas com outros profissionais ou ações em escolas e creches ${ }^{8}$, uma vez que, estudos mostram que a primeira infância parece ser o período ideal para introduzir bons hábitos e adotar padrões de comportamento em longo prazo 9 . Sendo assim, é importante ressaltar que, para além da consulta odontológica, os cuidados com a saúde bucal e orientações referentes são responsabilidade de toda a equipe de saúde, conforme preconiza o trabalho em APS.

Sendo assim, espera-se um conhecimento mínimo em saúde bucal de todos os profissionais que assistem crianças em puericultura, bem como, dos familiares e responsáveis pelas mesmas. A cronologia de erupção dentária, a sintomatologia dolorosa e irritativa que pode relacionar-se ao aparecimento dos dentes e a conduta diante da situação, estão entre os temas que devem ser dominados pela equipe ${ }^{10,6,11}$. Outras informações consideradas relevantes que seja de conhecimento da equipe, dizem respeitoaos agravos resultantes do uso prolongado do bico e chupeta, bem como, da sucção do dedo, que são denominados hábitos deletérios, uma vez que, alteram o desenvolvimento das estruturas ósseas bucais, podendo resultar em palato em ogiva e mordida aberta e/ou cruzada, sabendo-se que a remoção desse hábito até por volta dos 3 anos de idade tende a ocasionar uma correção natural do desenvolvimento da arcada dentária ${ }^{10,6,11}$.

Além disso, o momento ideal para introdução de novos alimentos, nos casos em que ocorre o aleitamento materno exclusivo, que é por volta dos 6 meses de vida, deve ser de conhecimento de todos. O que vem a ser alimentação saudável, da mesma forma, deve ser conhecida e estimulada, evitando-se alimentos açucarados e mamadeira noturna devido ao seu potencial cariogênico ${ }^{8}$. As vantagens do aleitamento materno na saúde da criança, mais especificamente na saúde bucal, também é conhecimento a ser compartilhado. A amamentação relaciona-se com o desenvolvimento das estruturas faciais, com a deglutição e fonação. No que diz respeito à higiene bucal, essa deve ser iniciada com a erupção dos primeiros dentes decíduos, recomenda-se a escovação com escova multicerdas em tamanho apropriado a idade e uso de dentifrício fluoretado com flúor (mínimo 1100 ppm) em pequena quantidade, equivalente a um "grão de arroz" 12, 13, 6, 10, a fim de evitar a deglutição do produto o que pode estar associado à fluorose dentária na dentição permanente ${ }^{6,10,14}$, tais informações são essenciais para garantir o desenvolvimento saudável da criança considerando a saúde bucal e seu impacto sistêmico.

Sendo assim, vale refletir se os profissionais e familiares percebem os motivos que levam o acompanhamento odontológico ser algo importante, e que deve ser estimulado desde o primeiro ano de vida, para além do senso comum. Portanto, o objetivo do presente trabalho foi avaliar a percepção de uma equipe de saúde de APS e dos familiares de crianças menores de dois anos quanto à importância da atenção à saúde bucal no primeiro ano de vida. 


\section{MÉTODO}

O presente estudo trata-se de uma pesquisa de natureza aplicada com abordagem qualitativa descritiva e exploratória.

O local de realização do estudo foi a Unidade de Saúde Nossa Senhora Aparecida (US NSA) do Serviço de Saúde Comunitária do Grupo Hospitalar Conceição. Trata-se de uma unidade de APS em que atua uma equipe multidisciplinar responsável por uma população de 5.756 moradores A cada ano, nascem cerca de 77 crianças, sendo que 92\% iniciam a puericultura nos primeiros dez dias de vida, quer seja em consulta individual ou coletiva. Os últimos resultados ${ }^{15}$ indicam que $72 \%$ das crianças passam também por uma consulta odontológica no primeiro ano de vida.

De forma a avaliar as percepções e conhecimentos de profissionais de saúde e usuários acerca da importância dos cuidados em saúde bucal no primeiro ano de vida, foram realizadas 3 entrevistas individuais em profundidade e 2 grupos focais. Os sujeitos do estudo foram selecionados de forma intencional, a fim de contemplar os objetivos propostos, sendo assim, compunham a amostra profissionais de saúde que trabalham na equipe da US NSA, não sendo odontólogos, e familiares de crianças menores de 2 anos que compareceram às consultas de puericultura coletivas e consultas individuais. Cabe ressaltar aqui que os usuários deveriam residir na área de adscrição da Unidade de Saúde, não apresentar incapacidade cognitiva e terem mais de 18 anos. Além disso, esse trabalho foi previamente aprovado pelo Comitê de Ética em Pesquisa do Grupo Hospitalar Conceição(número do CAAE: 81112517.8.0000.5530) e todos os participantes assinaram o Termo de Consentimento Livre e Esclarecido, respeitando os pressupostos éticos da Resolução CNS/MS 466/12.

Para a realização das entrevistas, foram previamente elaborados tópicos que guiassem a discussão acerca do tema, com base científica visando às recomendações de saúde bucal infantil do Ministério da Saúde ${ }^{8}$ e do Protocolo de Saúde da Criança do SSC-GHC ${ }^{16}$. Sendo assim, os tópicos guias foram os seguintes:

- Importância da consulta com o dentista no primeiro ano de vida. Se achavam importante, porquê, como ficaram sabendo. Se tinham ideia da frequência com que deveriam consultar com o dentista.

- $\quad$ Período de erupção dos primeiros dentes decíduos (de leite), sinais e sintomas que podem estar associados à erupção dos dentes, conduta frente a esses sinais e sintomas.

- Introdução de novos alimentos: época ideal para introdução de alimentos que não o leite materno, o que deve ser evitado e motivos. A importância do aleitamento materno para o desenvolvimento das estruturas da cavidade oral.

- Hábitos deletérios, tais como: uso de chupeta e bico. Se fazem bem ou mal? Qual o motivo? Que período seria ideal para remoção desse hábito e por quê? 
- Higiene oral, período que deve ser iniciada, instrumentos a serem utilizados conforme faixa etária. Uso de creme dental, importância e quantidade.

- Cárie. O que significa? Dente de leite nasce com cárie? Relação cárie, alimentos e medicamentos.

Inicialmente foi realizado um grupo focal com os familiares de crianças menores de 2 anos que compareceram apenas às consultas individuais, totalizando 3 participantes - duas mães e uma avó. A intenção foi de propiciar a interação entre os participantes e a troca de experiências, além de favorecer um diálogo natural e a compreensão de questões inerentes às crenças e práticas ${ }^{17,18}$, e assim enriquecer a coleta de dados, desse modo, a discussão teve duração aproximada de 1 hora, sendo gravada e posteriormente transcrita para permitir análise dos e categorização dos dados.

Em um segundo momento, o grupo focal com profissionais da equipe de saúde da US NSA foi realizado com um total de 4 participantes, sendo uma médica de família, um enfermeiro, uma psicóloga e uma assistente social, todos sendo participantes de consultas coletivas quando se dá na presença de um odontólogo. O encontro teve duração aproximada de 45 minutos, a discussão foi gravada e posteriormente transcrita para permitir a análise dos dados.

Por fim, foram realizadas as entrevistas individuais em profundidade com os familiares de crianças menores de 2 anos que compareceram às consultas coletivas, pois esses não compareceram no dia e horário reservado a realização do terceiro grupo focal. Foi possível entrevistar 3 familiares - duas mães e um pai de crianças menores de dois anos. Cada entrevista teve duração média de 30 minutos, sendo todas gravadas e posteriormente transcritas.

Tanto os grupos focais como entrevistas individuais foram conduzidos pela autora do estudo, de modo que, a mesma atuou como moderadora, estimulando a discussão nos grupos e buscando aprofundar as informações obtidas nas entrevistas, não interferindo nas crenças e hábitos relatados pelos sujeitos da pesquisa.

A técnica de análise de dados utilizada nesta pesquisa foi a análise temática de conteúdo ${ }^{19}$. Inicialmente foi realizada a leitura flutuante da produção textual, seguida por uma leitura exaustiva do material e organizados em eixos temáticos, do qual emergiram categorias de análise. As categorias foram construídas à luz do referencial teórico sobre saúde bucal infantil ${ }^{8}$. A partir da transcrição das entrevistas, os dados foram analisados de forma a considerar palavras utilizadas repetidamente, concordâncias e respostas dadas em função de experiências pessoas, hábitos dos participantes e conhecimento adquirido ${ }^{18}$. Quanto à análise textual discursiva proposta foi realizada a desconstrução dos textos provenientes das entrevistas e o estabelecimento de relações, ou seja, a categorização ${ }^{17}$.A definição da amostragem final do estudo se deu pela saturação dos dados.

Visando sistematizar os dados obtidos, facilitar a compreensão e a conexão entre os mesmos os achados foram categorizados a fim de contemplar os objetivos propostos ${ }^{19}$. Desse modo, definiu-se Tempus, actas de saúde colet, Brasília, 13(3), 61-77, set, 2019. Epub Jul/2020 ISSN 1982-8829 
as seguintes categorias:

- Importância do acompanhamento da criança com a equipe de saúde bucal no primeiro ano de vida;

- Período de erupção dos primeiros dentes decíduosesinais e sintomas associados;

- Aleitamento materno e alimentação saudável e sua relação com a saúde bucal;

- Hábitos saudáveis e hábitos nocivos à saúde bucal;

- Cuidados com higiene oral e

- Mitos em relação a cárie dentária.

\section{RESULTADOS}

Após a transcrição dos dados obtidos, os mesmos foram sistematizados e as categorias nas quais os temas foram divididos estão apresentadas a seguir. Cabe ressaltar que a fim de manter o sigilo dos indivíduos participantes da pesquisa, esses foram identificados como: familiar de consulta individual, para aqueles que compareceram apenas às consultas individuais de puericultura; familiar de consulta coletiva, para aqueles que comparecem às consultas individuais e coletivas de puericultura e, por fim, profissionais, para os profissionais da equipe de saúde que realizam puericultura e participaram do estudo.

Importância do acompanhamento da criança com a equipe de saúde bucal no primeiro ano de vida

A dentista mesmo fala que é aconselhável cuidar da dentição da criança desde pequeninho. (Familiar de Consulta Individual)

Eu já ouvi falar que tem que começar a cuidar desde a época que ainda não tem dentes, mas a mãe dele, eu acredito, que não o tenha trazido nenhuma vez. (Familiar de Consulta Individual)

Não me recordo se foi explicado porque é importante levá-lo ao dentista, mas eu acho que é importante por que está começando a se formar a dentição. É uma coisa que vai para o resto da vida. (Familiar de Consulta Coletiva)

A grande maioria da população não tem um acesso adequado ao atendimento odontológico e se a gente começa a cuidar e orientar a mãe logo cedo, previne a cárie. A gente vê que a incidência de cárie quando a mãe começa a cuidar cedo quase não existe, percebemos isso no acompanhamento das crianças. (Profissional) 
Acho interessante já introduzir na familia o hábito da escovação. (Profissional)

Eu também vejo mais ou menos por essa lógica - da prevenção -, relacionado também ao consumo de açúcar na alimentação. (Profissional)

Desde cedo, tanto os pais como a própria criança, devem ter esse cuidado e esse entendimento de que a saúde bucal também faz parte da saúde. (Profissional)

\section{Período de erupção dos primeiros dentes decíduos e sinais e sintomas associados}

Eu acredito que quanto mais cedo o dente nasce, mais cedo eles perdem, será que isso é verdade? (Paciente de Consulta Individual)

Eu acho que é em torno de 5 ou 6 meses que nasce o primeiro dente. (Paciente de Consulta Coletiva)

Nós tivemos uma consulta com dentista, ele orientou e informou a época que os dentes nasciam, mas eu não lembro. (Paciente de Consulta Coletiva)

É no sexto mês que os dentes começam a nascer. (Profissional)

Pela minha experiência, em casa, eu acho que entre 6 meses a 1 ano o dente de leite tem de nascer. (Profissional)

Por causa do nascimento dos dentes a criança baba muito e fica irritadinha. (Paciente de Consulta Individual)

Eu acho que quando os dentes começam a nascer a criança fica muito irritada, causa dor. (Profissional)

As crianças babam muito quando os dentes estão nascendo, mas e a febre dos dentes, é mito ou verdade? (Profissional)

Quando o dente está incomodando eu dava alimentos gelados, como água, e evitava coisas que pudessem machucar. (Paciente de Consulta Coletiva)

Eu costumava colocar o mordedor na geladeira para aliviar o incômodo do dente nascendo, mas eu evitei dar o "nenedente" (anestésico) que todo mundo dizia para usar. (Paciente de Consulta Coletiva)

Eu indico usar o mordedor e prescrevo analgésico, paracetamol, quando a criança está muito irritadinha. Eu não recomendo usar xilocaína. (Profissional) 


\section{Aleitamento materno e alimentação saudável e sua relação com a saúde bucal}

Eu amamentei um ano, um ano e meio. Acho que é muito bom para as crianças, acalma e tranquiliza.Dizem que é bom para a estimulação da gengiva. (Familiar de Consulta Individual)

Me falaram que amamentar era importante para o desenvolvimento do corpo, para ela não ficar doente por causa das gripes e pra mordida, ajuda a ter mais força pra sugar. (Familiar de Consulta Individual)

Amamentar é importante para o desenvolvimento da face, não é? Da musculatura, dos dentes... Eu lembro que quando a criança não é amamentada pode ter retração da mandíbula. (Profissional)

Eu acho que amamentar influencia na posição dos dentes, evita que a mordida fique torta. E dar a mamadeira não é a mesma coisa, pois fica ais fácil da criança sugar o leite. (Profissional)

Eu acho que não tem muita idade pra evitar o açúcar, se até pra gente que é adulto isso não faz muito bem, imagina pra criança. (Familiar de Consulta Individual)

A minha avó dizia que muito doce pra criança não é muito bom, dai eu fico meio assim. (Familiar de Consulta Individual)

A minha tia dizia pra dar refri, eu dizia que não. Ela é muito nova, ela vai ter a vida toda pra tomar, eu dou suquinho e ela adora. (Familiar de Consulta Individual)

Eu oriento evitar dar açúcar, a criança acostuma e provoca cárie. (Profissional)

\section{Hábitos saudáveis e nocivos à saúde bucal}

Eu acho que prejudica, de repente, a dentição, não é? O uso do bico. (Familiar de Consulta Individual)

Eu acredito que o bico acalme um pouco a criança sabe, mas eu acho que não é uma boa, o ruim é tirar depois. (Familiar de Consulta Individual)

As crianças ficam com aquele formato da boca diferente, o céu da boca fica mais fechado, né? Muda toda a arcada, eu sei pela minha outra filha, que vai fazer vinte anos. Ela chupou bico até os oito e teve que botar aparelho. (Familiar de Consulta Individual)

Eu acredito que seja bom até um certo tempo, não é? (quanto a chupar bico). Fico curiosa se afeta os dentes que vem depois. (Familiar de Consulta Individual)

Eu já ouvi falar que o bico provoca má formação e desalinhamento dos dentes com o uso contínuo. (Familiar de Consulta Coletiva)

ISSN 1982-8829 Tempus, actas de saúde colet, Brasília, 13(3), 61-77, set, 2019. Epub Jul/2020 
Eu acho que bico influencia na formação da mordida. (Profissional)

Eu aprendi que não deve indicar o uso do bico, então eu não indico. (Profissional)

Acho que é meio que redução de danos. Quando a criança dorme pode-se tirar o bico, não precisa passar a noite inteira. Acho que tem a questão da idade para tirar o bico, que é 3 anos, não tenho certeza. (Profissional)

Quanto ao bico, se puder evitar melhor, mas, às vezes, também é importante em termos de tranquilidade pra mãe e para a criança. (Profissional)

Uma coisa que é importante, se aquilo ali faz muito sentido pra aquela família, seja pela questão da criança ser muito ansiosa, seja porque a mãe se sente sobrecarregada, acaba sendo uma forma de acalmar. (Profissional)

Uma coisa que eu tenho dúvida é a questão do fio dental, que eu não usei no meu filho. A outra dúvida é do creme dental. Eu usei sem flúor, mas já ouvi várias orientações diferentes dos dentistas. (Profissional)

\section{Cuidados com higiene bucal}

Eu recordo que, desde pequeno, o ideal seria passar alguma coisa na gengiva para limpar, mas até hoje, às vezes, eu me esqueço de escovar. (Familiar de Consulta Coletiva)

Eu acredito que se deva começar a escovar só quando a criança consome outros alimentos além do leite materno. (Familiar de Consulta Coletiva)

O dentista orientou a estimular e fazer a escovação, deixar a criança brincar com a escova, o problema é que ele só quer comer a pasta de dente. (Familiar de Consulta Individual)

Eu escovo sem usar o creme dental e na creche eles fazem o mesmo. (Familiar de Consulta Individual)

Eu acredito que a pasta de dente não faça bem, não é?, Ainda mais que eles usam para comer, eles vão engolir tudo, dai eu só sujo a cerdinha da escova. (Familiar de Consulta Individual)

Acho que se usa um paninho para limpar a gengiva no período que não tem dente e depois pode usar aquela dedeira e a escova. (Profissional)

Eu oriento as mães a começar a fazer a higiene da boca antes mesmo de ter dentes, para limpar a lingua, a bochecha... (Profissional)

Eu tenho dúvida se já pode usar o fio dental e se o creme dental pode ser com flúor? Eu já ouvi 
diferentes orientações. (Profissional)

\section{Mitos em relação à cárie dentária}

Eu sempre ouvi que criança que toma muito antibiótico vai nascer com cárie. (Familiar de Consulta Individual)

Eu acho que o antibiótico pode causar cárie, porque é uma medicação muito forte. (Familiar de Consulta Coletiva)

Eu acredito que as medicações que são açucaradas tem que cuidar, principalmente a amoxicilina. Eu nunca provei, mas se vê que é bastante açucarada. Esses dias eu estava olhando na bula e li que contém açúcar. (Familiar de Consulta Individual)

Antigamente eles usavam e diziam que a eritromicina era um medicamento que dava muita cárie, mas eu não sei se isso é mito ou não. (Profissional)

Eu ouvi alguma coisa sobre a salivação. Que quem saliva mais é mais dificil ter carie, não sei se é verdade ou não. (Profissional)

\section{DISCUSSÃO}

A partir da análise dos discursos dos participantes da pesquisa e não desconsiderando o fato de que a saúde bucal é construída também pelos atravessamentos que perpassam a vida dos indivíduos, tanto no âmbito dos valores e hábitos familiares, como da cultura e estrutura social ${ }^{2,20}$. No que diz respeito à percepção e conhecimento da importância do acompanhamento odontológico no primeiro ano de vida, observa-se que tanto familiares quanto profissionais relatam e compreendem a existência de algum grau de importância nessa assistência, entretanto, parece não haver clareza dos motivos pelos quais se preconiza esse acompanhamento.

O discurso tanto dos profissionais quanto familiares enfatizam questões importantes como a prevenção do desenvolvimento de patologias, especialmente a cárie dentária, a necessidade de orientação voltada à prevenção, a formação de hábitos familiares saudáveis e percebem a saúde bucal como parte da saúde geral do indivíduo. Resultado que vem ao encontro ao estudo ${ }^{20}$ que avaliou o conhecimento de pais e responsáveis sobre saúde bucal na primeira infância, onde 56\% dos entrevistados associaram a saúde bucal com a saúde geral.

Em relação à cronologia da erupção dentária e fatores relacionados a esse processo, o impacto positivo do aleitamento materno no desenvolvimento das estruturas orofaciais, a prevenção de hábitos deletérios como o uso do bico e a introdução de alimentação complementar de forma adequada, questões também consideradas fundamentais do acompanhamento odontológico ${ }^{11}$ não foramrelacionados espontaneamente à importância da assistência odontológica na primeira

ISSN 1982-8829 Tempus, actas de saúde colet, Brasília, 13(3), 61-77, set, 2019. Epub Jul/2020 
infância, tanto por parte de familiares como profissionais.

No que diz respeito ao conhecimento relacionado ao processo de erupção dentária parece que os familiares que compareceram à consulta coletiva apresentam um pouco mais de esclarecimento sobre o tema, à medida que, demonstraram ter conhecimento do período de início da erupção da dentição decídua - por volta dos 6 meses da idade ${ }^{11,10,6}$, bem como, condutas adequadas durante esse processo, além de evitar o uso de produtos contra indicados, tais como anestésicos locais ${ }^{11,10,6,8}$. Os profissionais de saúde parecem ter maior esclarecimento sobre essa temática, entretanto, esperavase, a partir das educações permanentes realizadas no SSC, um conhecimento mais aprofundado que não foi demonstrado, além disso, durante a entrevista, os profissionais relataram que parte do conhecimento apresentado sobre o tema era empírico e advinha de experiências pessoais.

Da mesma forma, quanto ao conhecimento acerca da relação entre amamentação, alimentação saudável e saúde bucal, os familiares de forma geral reconhecem e valorizam a importância do aleitamento materno, entretanto, relacionam essa prática mais a uma questão de saúde geral, não tendo muito claro o real impacto no desenvolvimento das estruturas orofaciais ${ }^{11}$.

Resultados semelhantes referem-se aos hábitos. Quando o consumo de açúcar foi abordado, houve consenso de que ele não agrega benefícios e que deve ser evitado em qualquer faixa etária. Entretanto, não foi correlacionado à manutenção da saúde bucal e o seu potencial cariogênico, bem como, ao impacto negativo do aumento da frequência de consumo de tais alimentos e a incidência de cárie ${ }^{8,21}$, o que demonstra que possivelmente esse conhecimento pouco aprofundado advém de meios externos de informação, além das consultas individuais e coletivas, o que viria de encontro com os achados de estudos anteriores que demonstraram que grande parte dos pais e responsáveis (56\%) obtinham informações de temas relacionados à saúde bucal na primeira infância por meio da mídia ${ }^{20}$. Quando os profissionais foram questionados sobre essa mesma temática, embora o conhecimento pareça vago, foram citadas correlações importantes entre saúde bucal e desenvolvimento musculoesquelético na vigência do aleitamento materno ${ }^{11,6,10}$, reconhecendo também que o uso da mamadeira é contra indicado, embora pareça não haver o conhecimento dos motivos pelos quais não se recomenda o uso, sendo eles, a associação com cárie precoce da infância quando produtos açucarados são administrados com o uso da mamadeira noturna ${ }^{21,22}$, da mesma forma, o consumo de açúcar foi relacionado ao desenvolvimento da cárie dentária, entretanto, não citando questões importantes relacionadas ao tema, como evitar o consumo do mesmo até os 2 anos de idade ${ }^{22}$, sabendo que existe relação direta entre o consumo frequente de açúcar de origem não láctea e a experiência de dentes decíduos cariados, obturados ou perdidos em pré-escolares na faixa etária de 36 a 78 meses $^{23}$.

Em relação a hábitos saudáveis e nocivos com a saúde bucal nos deparamos com um conhecimento pobre sobre o tema. Os familiares reconhecem hábitos que impactam negativamente na saúde bucal, como o uso prolongado do bico, entretanto, o conhecimento das implicações desse hábito e seu prejuízo para a formação esquelética e dentição da criança ${ }^{11,7}$ parece estar relacionado às 
vivências pessoais de cada indivíduo, sendo esse um determinante importante para o conhecimento de forma geral.

Os familiares identificam a importância de se evitar o consumo do dentifrício fluoretado no primeiro ano de vida, entretanto, não referiram relação com a fluorose dentária ${ }^{7,14}$. Quanto aos profissionais da equipe de saúde, também demonstraram pouco esclarecimento sobre o tema, especialmente quanto aos cuidados com higiene bucal nessa faixa etária e o efeito nocivo do uso prolongado do bico. Entretanto, cabe aqui chamar atenção para o bom entendimento e valoração dos profissionais quanto ao contexto familiar. Os profissionais abordaram a relevância de se compreender a cultura e os valores familiares ao qual a criança está exposta, de modo a considerar, também, a abordagem baseada na orientação para redução de danos.

Sobre os cuidados relacionados à higiene bucal nessa faixa etária, nos deparamos novamente com um discurso carente de maior conhecimento técnico sobre o tema. Observa-se que os familiares ainda tem acesso a informações desatualizadas, como a necessidade de higienização da gengiva e mucosas, anterior a erupção dentária, e a visão do dentifrício fluoretado enquanto um produto nocivo, acreditando que seu uso deve ser evitado, entretanto, não há evidência científica consistente que recomende evitar o uso de dentifrício fluoretado, sabendo que a criança deve estar exposta ao mesmo, entretanto, em quantidade adequada conforma a faixa etária, visando garantir a maior proteção anti-cárie e o menor risco de ocorrência de fluorose ${ }^{24}$. Desse modo, com base nos discursos dos profissionais, pode-se sugerir que as orientações vêm sendo fornecidas no serviço de saúde necessitam de atualização e educação permanente, uma vez que, apresentam conhecimento semelhante ao dos familiares, além disso, essas crenças possivelmente são reforçadas pelo conhecimento popular passado através de gerações, uma vez que, tais orientações eram comuns no passado. Além disso, nenhum dos participantes relacionou o cuidado com a higiene bucal com a prevenção de cárie dentária, de modo que, sabe-se que informar as mães quanto à relevância dos hábitos e cuidados com a higiene bucal resulta em redução da cárie dentária ${ }^{21,25}$.

No que diz respeito aos mitos relacionados ao desenvolvimento da cárie dentária, nota-se que tanto profissionais de saúde como familiares acreditam na relação do uso de medicamentos, especialmente antibióticos, com a ocorrência dessa patologia, demonstrando profundo desconhecimento da etiopatogênia da doença, que se relaciona com o desequilíbrio decorrente no processo de desremineralização dentária, em função da presença de biofilme microbiano e ingestão frequente de açúcares ${ }^{25}$. Apenas um familiar cita a pertinente relação existente na composição de medicamentos infantis que apresentam açúcar em sua formulação, desse modo, podendo ocasionar a cárie dental pela presença do composto açucarado e não em função do princípio ativo do medicamento.

Ao comparar os relatos entre os grupos, não se observou diferença significativa entre o conhecimento de saúde bucal de um modo geral. Familiares e profissionais, assim como familiares que participaram da consulta coletiva e os que compareceram apenas às consultas individuais, parecem ter conhecimento muito semelhante e superficial sobre o ponto de vista mais técnico 
acerca dos cuidados com saúde bucal. O conhecimento de todos esteve mais fortemente associado à experiência individual e familiar de cada sujeito. Sendo assim, reforça-se a importância da realização de ações educativas sistemáticas para os profissionais. Em relação aos usuários, deve-se priorizar ações educativas e preventivas no campo da saúde bucal que contemplem o contexto familiar e que reforcem o conhecimento dos pais, pois as crianças tendem a repetir hábitos aprendidos com seus pais, avós e responsáveis ${ }^{6,26}$.

Cabe ressaltar aqui alguns desafios encontrados durante a seleção da amostra e que inviabilizaram a participação de mais componentes nos grupos, sendo eles: a dificuldade de encontrar uma agenda comum de disponibilidade entre os profissionais e entre os usuários, a dinamicidade do território que resultou com que familiares que compunham a população do estudo já não residissem mais na área de adscrição da Unidade de Saúde, as rotinas de familiares que trabalham em horário comercial em locais que impossibilitaram as suas liberações e a existência de famílias imigrantes estrangeiras no território que faziam parte da população do estudo, mas que, no entanto, não tinham fluência ou domínio do idioma do país. Chamou-nos a atenção o fato de não conseguirmos reunir justamente os familiares que realizaram a puericultura de seus filhos de forma coletiva.

\section{CONSIDERAÇÕES FINAIS}

O cuidado odontológico no primeiro ano de vida consiste em uma estratégia fundamental para o estabelecimento de boas práticas de cuidado, de modo que, representa o primeiro passo em busca da construção de hábitos saudáveis para o indivíduo e visa orientar, informar e conhecer hábitos familiares relevantes nesse contexto, que podem impactar de diferentes formas na saúde bucal da criança. Além disso, é durante esse período que ocorrem diversas mudanças na cavidade oral, destacase o início da erupção da dentição decídua, o aleitamento materno, a introdução da alimentação complementar, o possível estabelecimento de hábitos deletérios e a realização da higiene oral, todos esses fatores de grande relevância ao desenvolvimento do indivíduo e determinantes para o estabelecimento ou não de uma saúde bucal adequada.

A partir da análise realizada, o cuidado com a saúde bucal no primeiro ano de vida é permeado por questões familiares importantes, bem como, relaciona-se com as práticas e conhecimento dos responsáveis sobre o tema, desse modo, parece necessário que se reforce abordagens familiares no sentido de reconhecer hábitos, culturas e valores bem estabelecidos na família, a fim de propor mudanças e intervenções adequadas às diferentes realidades.

Além disso, os profissionais de saúde demonstram um conhecimento superficial sobre saúde bucal na primeira infância e as boas práticas nesse sentido, de modo quetambém se baseiam em experiências pessoais quando há um desconhecimento sobre o tema. Considerando queo Serviço de Saúde Comunitária do Grupo Hospitalar Conceição implantou uma rotina de saúde bucal dentro da Ação Programática da Criança e que esse é um dos indicadores da qualidade da atenção prestada pelo serviço na APS, cabe reforçar continuamente a importância do conhecimento e integração da 
equipe, a fim de garantir adequado acesso e atenção em saúde bucal na primeira infância, assim, é pertinente que se realizem ações de educação permanente nas equipes, uma vez que, ações multiprofissionais destinadas aos usuários, ou seja, não voltadas para a capacitação, não garantem o compartilhamento adequado de conhecimentos mais consistentes.

\section{REFERÊNCIAS}

1. Instituto Brasileiro de Geografia e Estatística (IBGE). Diretoria de Pesquisas Coordenação de População e Indicadores Sociais. Tábua completa de mortalidade para o Brasil. Breve análise da evolução da mortalidade no Brasil. 2015 [acesso em 10 ago de 2017]. Disponível em: <ftp:// ftp.ibge.gov.br/Tabuas_Completas_de_Mortalidade/Tabuas_Completas_de_Mortalidade_2015/ tabua_de_mortalidade_analise.pdf

2. MACAMBIRA DSC, CHAVES ES, COSTA EC. Conhecimento de pais/cuidadores sobre saúde bucal na infância. Rev Saúde e Pesq. 2017; 10(3): 463 - 472.

3. CAMPOS RMC et al. Consulta de enfermagem em puericultura: a vivência do enfermeiro na Estratégia de Saúde da Família. Rev. esc. enferm. USP. 2011; 45(3):566-574.

4. VIDAL VUA. Puericultura e autonomia das mães: uma relação possível? Dissertação de Mestrado em Saúde Coletiva Universidade Federal Fluminense, Niterói, 2011. $115 f$.

5. LENZ ML, FLORES R. Atenção à saúde da criança de 0 a 12 anos. 2. ed. Porto Alegre: Hospital Nossa Senhora da Conceição S.A; 2014.

6. FAUSTINO-SILVA DD et al. Cuidados em saúde bucal na primeira infância: percepções e conhecimentos de pais ou responsáveis de crianças de um centro de saúde de Porto Alegre, RS. Revista Odonto Ciência. 2008; 23(4): 357 - 379.

7. FIRMINO LB, GOULART RR, BAVARESCO CS. Conhecimento em Saúde Bucal da criança e sua aplicação na prática de médicos de família. Rev APS. 2017; 290 (4): 587 - 591.

8. BRASIL. Ministério da Saúde. Secretaria de Atenção à Saúde. Departamento de Atenção Básica. A Saúde Bucal no Sistema Único de Saúde. Ministério da Saúde, Secretaria de Atenção à Saúde, Departamento de Atenção Básica. Brasília: Ministério da Saúde, 2018. 350 p. : 11.

9. HANNA LMO, NOGUEIRA AJS, HONDA VYS. Percepção das gestantes sobre a atenção odontológica precoce nos bebês. RGO. 2007; 55 (3): 271 -274.

10. DOS REIS ML, LUVISON IR, FAUSTINO-SILVA DD. Conhecimentos, práticas e atitudes de medicos e enfermeiros sobre saúde bucal na puericultura na APS.RFO. 2015; 20 (2): $164-171$. 
11. AMERICAN ACADEMY OF PEDIATRIC DENTISTRY (AAPD). Guideline on Infant Oral Health Care. nique challenges and treatment options. PediatricDentistry.2014; 35 (6): 137 141.

12. HUGO FN,ROSING CK,ARAUJO FB. Consenso do Simpósio sobre Riscos e Benefícios de Dentifrícios Fluoretados na Primeira Infância. RevFac Odontol. 2012; 53 (3): 41-42.

13. CURY, J. A. Uso de dentifrício fluoretado na $1^{\text {a }}$ Infância. JABO. 2013; 146.

14. OLIVEIRA MJ et al. Estimated fluoride doses from toothpastes should be based on total soluble fluoride. International Journal of Environmental Research and Public Health. 2013; 10 (11): 5726-5736.

15. BRASIL. Ministério da Saúde. Grupo Hospitalar Conceição. Gerência de Saúde Comunitária. Apoio Técnico em Monitoramento e Avaliação. Sistema de Informações em Saúde do Serviço de Saúde Comunitária (SIS-SSC/GHC). Boletim Informativo Mensal.dez. 2018. mímeo. contato:frui@ghc.com.br

16. BRASIL. Ministério da Saúde. Grupo Hospitalar Conceição. Serviço de Saúde Comunitária. Apoio Técnico em Monitoramento e Avaliação. Atenção à Saúde da Criança de $0 \mathrm{a}$ 12 anos $-3^{\circ}$ edição. Hospital Nossa Senhora S.A. 2018.

17. MELO PSL, ARAÚJO WP.Grupo focal na pesquisa em educação. 2010 [ [aceso em 20 ago de 2017]. Disponível em: http://leg.ufpi.br/subsiteFiles/ppged/arquivos/files/ VI.encontro.2010/GT.3/GT_03_10_2010.pdf

18. BARBOUR R. Grupos Focais. Artmed, Porto Alegre, 2010.

19. BARDIN L. Análise de conteúdo. São Paulo (SP). Edições 70. 2011.

20. GUARIENTI CA, BARRETO VC, FIGUEIREDO MC. Conhecimento dos Pais eResponsáveis Sobre Saúde Bucal na Primeira Infância. PesqBras emOdontoped e Clín Integr. 2009; 9 (3): $321-325$.

21. CANALLI CSE. Fatores associados à cárie dentária: uma pesquisa qualitativa na bebêclínica da UNIGRANRIO/RJ. Rev Rede Cuid Saúde. 2010. ISSN-1982-6451

22. MEDEIROS LF. Porque crianças com menos de 5 anos ainda tem cárie no Brasil. In: CONGRESSO BRASILEIRO DE ODONTOPEDIATRIA. 2015. Relatório de Simpósio.

23. FILHO MDS, CARVALHO GDF, MARTINS MCC. Consumo de alimentos ricos em açúcar e cárie dentária em pré-escolares. Arq em Odontol. 2010; 46 (3): 152 - 159. 
$77 / /$

24. CURY JA, TENUTA LMA. A evidence-based recommendation on toothpaste use. Brazilian Oral Res. 2014; 28 (esp): $01-07$.

25. DEMARI S et al. Avaliação do conhecimento sobre higiene bucal dos responsáveis por crianças de $0-6$ anos de idade. FOL. 2016; 26 (1): $11-18$.

26. SOARES IMV,SILVA AMRB,MOURA LFAD,LIMA MDM,NETTO OBS,MOURA MS. Conduct of pediatricians in relation to the oral health of children. Rev OdontolUnesp. 2013; 42 (4): $266-272$.

Artigo apresentado em setembro de 2019 Artigo aprovado em novembro de 2019 Artigo publicado em julho de 2020 